Deja CRNOVIĆ*

\title{
EVENTIZACIJA IN KOMODIFIKACIJA POLITIKE NA INSTAGRAMU**
}

\begin{abstract}
Povzetek. Politika 21. stoletja je zaradi mediatizacije, eventizacije in vdiranja tržne logike v politično polje vedno bolj personalizirana. V ospredju niso politike, temveč osebe, ki delujejo v političnem polju. Politiki in političarke so s svojim delovanjem blizu zvezdnikom in zvezdnicam, saj privid kompetence bolj kot v političnem delovanju črpajo v svoji zasebnosti oziroma osebnih vrednotah. Dosegajo ga z uprizarjanjem določenega spola in razreda, s pomočjo česar se v populistični maniri približujejo "ljudstvu" oziroma "navadnemu človeku". Članek analizira uprizarjanje moškosti in razreda ter posledično depolitizacijo prek Instagrama na primeru dveh predsednikov držav, Boruta Pahorja in Aleksandra Vučića. Čeprav oba predsednika v svojem domačem političnem polju delujeta populistično in občasno tudi domačijsko, na njunih profilih na Instagramu prevladuje uprizarjanje kozmopolitske, $v$ primeru Pahorja pa tudi nove, narcisoidne moškosti. Medtem ko Vučić daje prednost objavam s tujimi voditelji z mednarodnih srečanj, je pri Pahorju bistveno več fotografij iz njegove zasebnosti in domačega okolja.
\end{abstract}

Ključni pojmi: mediatizacija, depolitizacija, eventizacija, Instagram, politika, uprizarjanje, spol, razred

\section{Uvod}

Predsedniška kampanja Boruta Pahorja leta 2012 je bila v več pogledih posebna, saj je v njej Borut Pahor, nekdanji evropski poslanec, nekdanji predsednik državnega zbora in nekdanji predsednik vlade, opravljal 46 različnih poklicev: od smetarja do frizerja. Vsako opravljanje poklica je bilo dokumentirano s fotografijami, ki so jih iz Pahorjevega štaba posredovali medijem, ti pa so fotografije na svojih spletnih straneh objavljali v obsežnih fotogalerijah, včasih v političnih, včasih v zabavnih rubrikah. Fotograf Borut

\footnotetext{
* Dr. Deja Crnović, samozaposlenav kulturi, dejacrnovic@gmail.com.

** Izvirni znanstveni članek. DOI: 10.51936/tip.58.2.409-427
} 
Krajnc je iz fotografij, posnetih med kampanjo, ustvaril tudi koledar. Pahor je po tej kampanji leta 2012 postal predsednik države, na tem položaju je še danes. Zdaj ne opravlja več drugih poklicev, ima pa svoj uradni predsedniški profil na Instagramu s 128 tisoč sledilkami in sledilci, na katerem skoraj vsak dan objavi fotografijo; včasih iz predsedniške palače, včasih z obiska tujine, spet drugič s tekaške proge, domače naprave za fitnes, plaže. Pahor ni edini svetovni politični voditelj z bogatim profilom na Instagramu, tudi odnos do tega družbenega omrežja se je v zadnjih osmih letih precej spremenil, saj je postal skorajda nujen sestavni del političnega komuniciranja.

Posebnost družbenih medijev je, da imajo na njih nadzor nad objavljanjem vsebin in njihovim uokvirjanjem politiki in političarke oziroma njihovi svetovalci in svetovalke, strokovnjaki in strokovnjakinje za odnose z javnostmi, ne pa na primer novinarji in novinarke oziroma uredniki in urednice. Medtem ko se nekateri politiki najraje poslužujejo kratkih, besedilnih objav na Twitterju (Donald Trump, Janez Janša), se drugi precej bolj posvečajo objavljanju podob na Instagramu (Borut Pahor, Justin Trudeau, Aleksandar Vučić). S tem ko osebe v politiki svoja sporočila in fotografije objavljajo na družbenih omrežjih, novinarji in novinarke izgubljajo monopol nad javnimi informacijami, zato Ekman in Windholm (2015) govorita o mediatizirani soodvisnosti, kjer so tako osebe v medijskem kot v političnem polju odvisne druga od druge pri opravljanju svojega dela. Ko so tako novinarji in novinarke kot politiki in političarke "medijski akterji in »medijski viri«, se spremeni tudi razmerje moči; politiki in političarke se vedno bolj lahko zanašajo na lastno medijsko produkcijo, s tem pa imajo tudi večji nadzor nad svojo podobo v javnosti.

V nadaljevanju bomo zato pogledali, kaj se dogaja s političnim poljem v mediatizirani družbi, kako se to vedno bolj depolitizira in kakšno vlogo ima pri depolitizaciji uporaba družbenih omrežij, predvsem Instagrama. $S$ pomočjo analize Instagram profilov dveh predsednikov držav, Boruta Pahorja in Aleksandra Vučića, ki sta si svetovnonazorsko na prvi pogled precej različna, bomo poskušali detektirati načine, na katere je njuno politično delovanje personalizirano, eventizirano in posledično depolitizirano. $\mathrm{V}$ analizi se bomo osredotočili predvsem na njuno uprizarjanje moškosti in razreda na Instagramu. Oba sta namreč v svoji dolgoletni politični karieri prestala številne transformacije, kot predsednika držav pa morata po eni strani za domače občinstvo uprizarjati bolj domačijsko različico moškosti, po možnosti delavskega razreda, za tuje občinstvo pa buržujsko-racionalistično moškost, ki je bolj primerna za uprizarjanje moškosti v mednarodni politiki. Zanimalo nas bo, kako se v njunih objavah na Instagramu odraža njuna politika, če sploh, z analizo objav v izbranem obdobju leta 2020 bomo skušali kategorizirati objave po njihovi vsebini in tako dobiti oris prevladujočih tem na profilih, $\mathrm{z}$ analizo posameznih objav pa razbrati »namen« objav 
ter kako se predsednika v svojih objavah na družbenem omrežju, ki nagrajuje pozitivne vsebine, razlikujeta.

\section{Mediatizacija družbe in politike}

Ne glede na vrsto prevladujočega medija živimo v mediatizirani družbi (Couldry in Hepp, 2013), v kateri so mediji ključna referenčna točka za dojemanje in razumevanje sveta in družbe. To pomeni, da večino informacij, ki jih imamo o družbi, prejmemo prek medijev - tudi če govorimo o neposredni komunikaciji med osebami v živo, bo dojemanje obravnavnih vsebin še vedno močno odvisno od tega, kako so bile prej posredovane prek medijev in na kakšen način so bile uokvirjene. Mediji oziroma medijsko polje niso avtonomni, temveč so podvrženi številnim zunanjim dejavnikom. Medijsko in politično polje vzajemno vplivata drug na drugega, na medijsko polje pa vpliva tudi tržna logika. Posledično to pomeni, da v politično polje prek medijskega vdirajo različni diskurzi, ki so bližje tržni logiki. Takšni so na primer zvezdniški diskurz (Street, 2003, 2004; van Zoonen, 2005), zaradi česar je politika vedno bolj personalizirana (van Santen in van Zoonen, 2010), torej osredotočena na posamezne političarke in politike, ter (epizodično) uokvirjanje (Iyengar, 1991), značilno za medijsko logiko (Altheide in Snow, 1979), zaradi česar je politika vedno bolj eventizirana (Saxer, 2007), torej osredotočena na dogodke in občutja. Tržna logika s seboj prinaša tudi t.i. banalizacijsko silo. »[Č]im širšo publiko si hoče pridobiti nek medij ali katero koli sredstvo izražanja, tem bolj se mora znebiti ostrine, vsega, kar bi lahko ločevalo, razdvajalo« (Bourdieu, 1996/2001: 39). Bolj ko je nek medij bran/gledan/poslušan, bolj se ogreva za omnibusne teme, ki ne načenjajo problemov, ki naj ne bi nikogar šokirale, glede katerih se vsi strinjajo, ki ne razdvajajo ljudi, se vsem zdijo zanimivi, »vendar na tak način, da se ne dotaknejo ničesar pomembnega (Bourdieu, 1996/2001: 15). Objave politikov in političark na družbenih omrežjih, kjer imajo sami nadzor nad vsebino, predvsem na Instagramu, sledijo podobni logiki - čim manj vsebin, ki bi lahko razdvajale, čim več vsebin, ki prinašajo všečke.

\section{Personalizacija in eventizacija politike}

Ker se politika ne zanaša več na skupne družbene lastnosti svojih volivk in volivcev, mora svoje volilno telo šele "ustvariti« na podlagi privlačnosti svojih strank oziroma kandidatk in kandidatov (van Zoonen, 2005: 59). S tem prihaja do personalizacije politike, politična komunikacija pa je vedno bolj neracionalna in usmerjena k dogodkom, občutjem in izkustvom (Saxer, 2007: 185). Pri medijski»kolonizaciji« politike se s prevladujočim vplivom zabavne medijske kulture področje zasebnosti začne širiti na javno, kar je še posebno 
koristno v politiki, kjer akterji vedno težje dajejo obljube, saj rezultati niso odvisni zgolj od njih; veliko lažje poudarjajo in prodajajo svojo osebnost in zasebnost. Personalizacija osebe $\mathrm{v}$ politiki približuje zvezdniškemu statusu, ki pa ga ti večinoma ne dosežejo po naključju, temveč z zavestnim delovanjem $\mathrm{v}$ smeri pridobivanja pozornosti in projiciranja določene podobe. Zvezdništvo postane utelešenje diskurzivnega boja o normah individualnosti in osebnosti znotraj kulture (Marshall, 1997: 65), zato je (zvezdniško) tekmovanje za uspeh tudi tekmovanje prevladujočih družbenih vrednot.

Politična persona temelji na performansu, ki je sestavljen iz določene mere samozavedanja in kalkulirane prevare, ker pa performans poleg družbenega življenja vključuje tudi zasebno, so pri političnih personah vedno bolj v ospredju osebne, in ne politične vrednote (Corner, 2000: 391-394), ki jih je treba predstaviti prek dogodkov, o katerih nato poročajo mediji ali pa so objavljeni na družbenih omrežjih. Medijski dogodki so "prekinitve rutine« in »oblika komunikacije» (Hepp in Couldry, 2010: 10), mediji, še posebno televizija, pa dogodke potrebujejo za svoje vsakodnevno delovanje. S spremembami $v$ medijskem polju, kjer je zaradi finančnih omejitev vedno manj specializiranega novinarstva in vedno večji pritisk na proizvajanje velike količine novic, se "novinarske zgodbe« pogosto zreducirajo na izjave in podobe, ki povzemajo, poenostavljajo oziroma kondenzirajo kompleksne politične procese v eni podobi (Wodak, 2011). Pri tem že same izjave in podobe, če so dovolj novinarsko zanimive, postanejo dogodki.

\section{Družbeni mediji in mediatizacija}

Vsako družbeno omrežje ima svoje značilnosti, kot so struktura omrežja, funkcionalnost, algoritmi in modeli datafikcije oziroma načini, na katere se vsebino pretvarja v podatke. Gilroy-Ware (2017) kljub razlikam med omrežji izpostavlja štiri glavne značilnosti časovnice družbenih omrežij: viri novic so uporabniku oziroma uporabnici večinoma "poznani«, saj jih je izbral/a sam/a (jih dodal/a, jim sledi, je z njimi prijatelj/ica), časovnica je navidez neskončna, torej daje vtis, da vsebin ne bo nikoli zmanjkalo, mešanica vsebin je prilagojena posamezniku ali posameznici in ne sledi več klasičnim delitvam na žanre ali formate, ter občutek novosti in nepredvidljivosti, torej občutek, da bo ob vsakem obisku omrežja uporabnik ali uporabnica videla nekaj novega. Obiskovanje družbenih omrežij po Gilroy-Ware tako nima za cilj zgolj informiranja, temveč tudi zadovoljevanje čustvenih potreb, na primer potrebe po zabavi in pozitivnih novicah kot distrakciji, ki pripomore k čustvenemu preživetju posameznika ali posameznice (Gilroy-Ware, 2017: 169). Na družbenih omrežjih so bolj kot informacije v ospredju afekti in prepričanja, zato je vedno bolj pomembno tudi uprizarjanje čustev. Medtem ko tradicionalno novinarstvo stremi predvsem $\mathrm{k}$ objektivnosti, tako $\mathrm{v}$ 
novinarstvu kot na družbenih omrežjih v ospredje prihajajo čustva, ki se v političnem polju uprizarjajo strateško in glede na družbeni kontekst (WahlJorgensen, 2019). Z informalizacijo (po Wouters, 2007) političnega polja in vedno večjo vlogo osebnih in čustvenih narativov se spreminja tudi narava politične komunikacije. Čeprav po Wouters (2007) s tem pride do »emancipacije« čustev, pa to s seboj prinaša tudi potrebo po vedno večji samoregulaciji oziroma samonadzoru akterjev. S tem ko politiki in političarke sami postanejo medijski producenti, »breme« zabavanja občinstva, s tem pa tudi strateškega uprizarjanja čustev in njihove osebnosti, pade na njih. Družbena omrežja s svojo čustveno infrastrukturo pod vprašaj postavljajo strogo ločitev med zasebnim in javnim, individualnim in kolektivnim ter osebnim in političnim (Wahl-Jorgensen, 2019), samouprizarjanje pa postane pomemben del političnega delovanja.

V primerjavi Facebooka, Twitterja, Snapchata in Instagrama Bossetta (2018) ugotavlja, da je Twitter predvsem medij reakcij, torej družbeno omrežje, na katerem se objave navezujejo predvsem na (politične) dogodke v drugih, klasičnih medijih. Instagram tovrstne časovne odvisnosti nima oziroma za razliko od Twitterja ne služi kot »drugi ekran«(Larsson, 2017). Larsson (2017) na podlagi analize volitev na Norveškem ugotavlja, da je Twitter večinoma dojet kot elitni medij, ki ga uporabljajo predvsem ljudje na položajih moči, kot so politiki in političarke ter zaposleni in zaposlene $\mathrm{v}$ medijih in na področju odnosov z javnostmi, medtem ko so uporabniki in uporabnice Instagrama mlajši, "navadni« ljudje. $Z$ vidika čustvene arhitekture je Twitter medij razuma, pa tudi sovraštva, »trolanja« in negativnih čustev, medtem ko na Instagramu več pozornosti dobijo pozitivne vsebine (Wahl-Jorgensen, 2019) oziroma kot je razliko opisala britanska konservativna političarka Nadine Dorries (v Hinsliff, 2019): »Twitter je za politiko. Instagram je za ljudi, ki so mi všeč, in stvari, ki jih želim videti."

Instagram je medij strateške samoreprezentacije, kar pomeni, da gre za namerno izbrane in predstavljene rutine delovanja, pogosto s pomočjo zasebnih fotografov ali fotografinj s privilegiranim dostopom, ki jih politiki ali političarke najamejo za beleženje uradnih in polzasebnih situacij. Na ta način posnete fotografije lahko predstavljajo tako resne opravke in vladne zadeve, kot so srečanja $\mathrm{z}$ drugimi politiki in političarkami, pa tudi vpogled v zakulisje ali zasebno življenje (Marland, 2012). Prav fotografije slednjega pripomorejo $\mathrm{k}$ »normalizaciji " politika ali političarke in k projekciji njegove oziroma njene avtentičnosti. »Hobiji in druge prostočasne dejavnosti nakazujejo vidike njihove osebnosti zunaj politične arene ali iz časov pred njenim začetkom« (Liebhart in Bernhardt, 2017: 20). Objavljanje na družbenih omrežjih pogosto pomeni, da so politiki in političarke $\mathrm{v}$ permanentni digitalni kampanji, hkrati pa jim objavljanje na družbenih omrežjih omogoča, da zaobidejo tradicionalne medijske posrednike in neposredno naslovijo 
občinstvo (Lalancette in Raynauld, 2019). Vzpon politične rabe družbenih omrežij po Ekmanu in Windholmu (2015) pripomore h komodifikaciji politike, zvezdniški politiki oziroma konstrukciji individualiziranih, oznamčenih politikov in političark, prek komunikacije na družbenih omrežjih pa je politika posledično vedno bolj depolitizirana. Personalizacija politike tako ni zgolj posledica komercializacije novic in vdiranja tržne logike v uredniško politiko, temveč tudi posledica bolj personaliziranega delovanja in komunikacije politikov in političark (Ekman in Windholm, 2015), tudi na družbenih omrežjih.

\section{Uprizarjanje spola in razreda $\mathrm{v}$ politiki}

Uprizarjanje oziroma performativnost spola (Butler, 2006/1999) pomeni, da spol ni biološka danost, temveč nekaj, kar je treba ves čas uprizarjati s ponavljanjem dejanj in lastnosti, ki jih družba pripisuje moškim ali ženskam. Moškosti se večinoma pripisujejo fizična in mentalna moč, tekmovalnost, agresivnost, dominantnost, racionalnost, nečustvenost in objektivnost (Elinor Ochs, 1992) s pozitivnim predznakom, kar jih uvršča pred oziroma nad lastnosti, ki praviloma pritičejo ženskosti, kot so mehkoba, čustvenost 414 in skrb (Beynon, 2002: 56). "Ženske lastnosti« so še vedno dojete kot manj zaželene, tudi - oziroma še posebno - pri moških. Ker pa je spol stvar uprizarjanja, je moškosti in ženskosti več, tudi znotraj političnega polja. Ena od oblik privilegirane moškosti, najpogosteje prisotne v (mednarodni) politiki, je buržujsko-racionalistični model, ki ga opisuje Hooper (2001). Ta model izvira iz mednarodne politične sfere in je model manj agresivne, bolj egalitarne in demokratične moškosti. Idealizira tekmovalni individualizem, razum, samonadzor in samozanikanje. Kombinira spoštovanje in preračunljivo racionalnost v javnem življenju, superiorni intelekt in osebna integriteta pa sta bistveno bolj cenjena kot fizična moč ali pogum. Gre za moderno obliko moškosti, prvo obliko novega moškega, ki je tesno povezana z razsvetljenstvom in moderno državo ter razvojem kapitalizma (Hooper, 2001: 88). V 80. letih prejšnjega stoletja sta se predvsem v Veliki Britaniji in njenem revijalnem tisku pojavili dve narcisoidni obliki nove moškosti, in sicer novi moški (New Man) in novi fant (New Lad), obliko nove moškosti skrbnika pa najdemo na primer v ZDA, kjer v 70. in začetku 80. let nastopi podoba novega očeta, ki se oblikuje kot nasprotje tradicionalni, neekspresivni, hipermaskulini moškosti (Messner, 1993), ki se vedno bolj premešča na nižje razrede. Novi moški narcis je posledica spremenjenih družbenih razmer in razmerij med spoloma, tudi posledica komercializacije moškosti in ekspanzije potrošništva po drugi svetovni vojni. Tako kot podoba novega očeta je tudi splošna kulturna podoba novega moškega podoba belega, heteroseksualnega moškega iz srednjega ali višjega razreda, pri katerem premik v osebnem in življenjskem slogu 
predstavlja odmik od tradicionalne moškosti, ki jo privilegirani moški vidijo kot nezdravo ali čustveno omejujočo. Poznokapitalistična družba, ki jo opisuje Lasch (2012), spodbuja vzpon narcističnega osebnostnega tipa, ki predstavlja psihološko razsežnost splošne družbene odvisnosti od države, korporacije in drugih birokracij. "Narcis namreč kljub občasnim iluzijam o lastni vsemogočnosti potrebuje druge, da potrjujejo njegovo samospoštovanje. Ne more živeti brez občudujočega občinstva" (Lasch, 2012: 28), svojo negotovost pa lahko premaga le tako, da $\mathrm{v}$ pozornosti drugih vidi odsev svojega grandioznega jaza. Narcisoidna nova moškost tako svojo zadovoljitev lahko najde na družbenih omrežjih, posebej na Instagramu, ki s svojo čustveno arhitekturo preferira predvsem pozitivne podobe in odzive.

Vendar pa so nove moškosti predvsem moškosti privilegiranega razreda in so posledično v političnem polju, z vidika populizma, manj učinkovite. Laclau (2008) populizem definira kot diskurzivno strategijo, ki konstruira politično fronto, ki razdeljuje družbo na dva tabora in poziva k mobilizaciji tistih z manj moči proti tistim na oblasti. Po Laclauu populizem ni ideologija in ga ne moremo pripisati specifični programski vsebini, niti ni politični režim. Je način ustvarjanja politike, ki lahko prevzame številne ideološke oblike glede na čas in kraj in je kompatibilen z vrsto institucionalnih okvirov. Po Kalbu (2011) populizem v trenutni situaciji pomeni zavračanje liberalnih, kozmopolitskih elit, ki svetovnih virov, ki so na voljo, ne znajo izkoristiti za potrebe lokalnega prebivalstva. Posledica tega so generacije telegeničnih in karizmatičnih ideologov, ki rušijo vzpostavljene politične razrede in institucije.

Moškost delavskega razreda v nasprotju z novo moškostjo ponuja tradicionalne vrednote, povezane s predindustrijskim obdobjem, ko je večja fizična moč pomenila večji zaslužek. Medtem ko moški srednjega razreda lahko pridobivajo institucionalno moč, lahko moški delavskega razreda pridobivajo fizično moč in posledično pogosto prevzemajo mačo identitete, da bi z njimi prekrili svojo nemoč, ki jo kompenzirajo tudi z dominantnostjo v domačem okolju (Beynon, 2002: 20). Medtem ko je moškost delavskega razreda $\mathrm{v}$ kapitalizmu podrejena moškost, pa se nekatere njene lastnosti zrcalijo v uspešnih poslovnežih in politikih. Moškost delavskega razreda ima zato oznako nekakšne hipermoškosti, še posebno v primerjavi z moškostjo srednjega razreda (Hooper, 2001: 71), v političnem polju, še posebej v notranji politiki, pa prinaša »dividende«. Tako na primer ugotavljata Riabov in Riabova (2014: 23), ki na primeru Putinove Rusije opažata »remaskulinizacijo Rusije«, torej identitetno politiko, usmerjeno k ustvarjanju pozitivne kolektivne identitete Rusije. Vzroke za remaskulinizacijo Rusije pod Putinom najdeta med perestrojko v začetku postsocialističnega obdobja, ko je padec socializma zahteval »normalizacijo« razmer in vrnitev k "naravnemu redu stvari«, v katerem imata strogo določeni mesti tudi moški 
in ženski spol. Ruski množični mediji po Riabovu in Riabovi (2014: 26) Putinovo podobo maskulinizirajo s pomočjo militarizacije in erotizacije ter uporabo besede mužik kot simbola prave moškosti, ki je sprva označevala kmeta, danes pa predstavlja hegemono moškost, moškost, ki temelji na ekonomski neodvisnosti, samozadostnosti, moči, redkobesednosti, poudarku na dejanjih; mužik ni politično korekten in se ne zadržuje pri izražanju seksizma in homofobije. Putin, ki je sprva ustrezal zahodnjaškemu racionalnemu tipu moškosti - bil je hladen, pragmatičen in racionalen menedžer -, se je sčasoma preobrazil v moškega bližje modelu mužika (2014: 27). Glede na to, da se tudi slovenska in srbska družba po razpadu Jugoslavije in samoupravnega socializma soočata s podobnimi premiki, ne preseneča, da tako pri Pahorju kot pri Vučiću najdemo lastnosti domačijske hipermoškosti, ki se prepletajo z buržujsko-racionalistično moškostjo mednarodne politike.

\section{Študiji primera}

\section{Borut Pahor}

Borut Pahor je svojo politično pot začel v Zvezi socialistične mladine Slovenije konec 70. let prejšnjega stoletja, leta 1997 je postal predsednik Združene liste socialnih demokratov. Leta 2004 je bil izvoljen v Evropski parlament, leta 2008 pa je po državnozborskih volitvah postal predsednik vlade. Septembra 2011 je bila njegovi vladi izglasovana nezaupnica, istega leta pa se je odločil, da kandidira za predsednika države. Pahorjeva kampanja za predsednika države je bila skrajno eventizirana, sestavljena iz dogodkov, ki niso bili neposredno povezani s kandidaturo za najvišjo funkcijo $\mathrm{v}$ državi, a so bili zaradi svoje nenavadnosti medijsko privlačni. Pahor je pred predsedniškimi volitvami 2012 prostovoljno opravljal 46 različnih poklicev, opravljal je večinoma fizična dela - bil je na primer smetar, cestar, mesar, gozdar, gasilec in frizer. Pri tem ni šlo za privatizacijo kampanje, saj z opravljanjem del ni razkrival svojega zasebnega življenja, temveč je šlo za personalizacijo oziroma humanizacijo, pri čemer je bil namen predstaviti svojo "človeško«, "sproščeno« ali celo zabavno plat (glej Driessens in dr., 2010). Pahor se je za potrebe kampanje »prelevil « v moškega delavskega razreda, ki pred videz postavlja opravljeno delo, moralo in solidarnost (Crnović, 2014), pri tem pa lahko zaznamo tudi poteze domačijskosti. Popolna eventizacija kampanje, ki je temeljila na prikazovanju sposobnosti kandidata, na primer telesne pripravljenosti in sposobnosti za fizično delo, je Pahorju omogočila večjo medijsko vidnost, predvsem pa z njo postavil temelje za svoje bodoče politično komuniciranje, saj se je z vzponom uporabe Instagrama tudi sam "preselil« na to družbeno omrežje, kjer še danes, kot bomo videli v nadaljevanju, komunicira predvsem prek podob. 


\section{Aleksandar Vučić}

Aleksandar Vučić je svojo politično kariero začel leta 1993, ko je bil izvoljen kot poslanec Srbske radikalne stranke. Leta 1998 je postal minister za informiranje, v času, ko je bil predsednik Srbije Slobodan Milošević. Vučić je v tem obdobju znan po uvedbi kazni za novinarje, ki so bili preveč kritični do Miloševićevega režima. Leta 2008 se je pridružil novoustanovljeni Srbski napredni stranki in leta 2012 postal njen predsednik. Srbska napredna stranka je vsaj na začetku imela večino članstva iz Srbske radikalne stranke, zaradi česar jih mnogi imenujejo tudi "neoradikali« (Jovanović, 2018). Kratek čas je bil minister za obrambo in prvi podpredsednik srbske vlade (pred njim ta pozicija ni obstajala). Leta 2014 je postal predsednik vlade, leta 2017 pa predsednik države. Na volitvah leta 2020 je znova zmagala njegova stranka, ob bojkotu opozicijskih strank pa trenutna sestava srbskega parlamenta nima dejanske opozicije.

Kot ugotavlja Jovanović (2018), so medijske reprezentacije Aleksandra Vučića v srbskih medijih, predvsem tabloidih, ki so vidno naklonjeni Vučiću, kompleksne. V analizi naslovov se sočasno pojavlja diskurz žrtve, v katerem je Vučić predstavljen kot tarča načrtovanega, vendar vsakič znova spodletelega poskusa atentata, kot diskurz Übermenscha, ki ponuja razlog, zakaj naj bi bil Vučić ves čas žrtev poskusov atentata: je preveč sposoben, močan in uspešen, zaradi česar Jovanović (2018: 31) ugotavlja, da se gradi videz predsednika, ki je brez strahu in ki je kompetenten, kljub temu da je ves čas pod udarom. Hkrati uprizarja "pretirano moškost«, torej patriarhalno "pravo "moškost, pri čemer je vsak, ki se mu postavi naproti, vsaj »biseksualen«, zato ne čudi, da je ena glavnih žaljivk, usmerjenih proti Vučiću, ki jo je mogoče slišati tudi na številnih demonstracijah proti njemu, »Vučiću pederu «. ${ }^{1}$ Jovanović primerja medijske reprezentacije Vučića z medijskimi reprezentacijami Viktorja Orbana, Recepa Tayyipa Erdogana in Vladimirja Putina, medtem ko Kulić (2020) komunikacijo Vučića primerja s komunikacijo Donalda Trumpa in ugotavlja, da oba izkoristita večino priložnosti, da se "prepirata $z$ novinarji in novinarkami, le da so Trumpovi napadi bolj osebni, medtem ko Vučić svojo kritiko novinarjev in novinark premešča na »zunanje naročnike« ali »opozicijo«. Aleksandar Vučić je tako v svojem slogu komuniciranja precej bližje Janezu Janši kot pa Borutu Pahorju, vendar pa, kot bomo videli v nadaljevanju, je njegova politična komunikacija na Instagramu bistveno drugačna od njegove medijske reprezentacije $\mathrm{v}$ »tradicionalnih» medijih.

1 Dostopno prek http://hr.n1info.com/Regija/a182408/Vucic-snimio-predizborni-spot-Vucicu-pederu. html, 10. 3. 2021. 


\section{Analiza profilov Aleksandra Vučića in Boruta Pahorja na Instagramu}

Ob personalizaciji in eventizaciji politike, ko politiki in političarke vedno bolj postajajo podobni zvezdnikom in zvezdnicam, je zasebna sfera tista, iz katere politik ali političarka črpa svojo kredibilnost (Luthar, 2008). Ultimativna politična zvezda je tako sposobna uravnotežiti nasprotujoče si zahteve politike in zvezdništva in se pozicionirati točno na sredino: projicira persono, ki ima izkušnje v politiki, a je še vedno outsider ali outsiderka (van Zoonen, 2005). Kot bomo videli v nadaljevanju, sta oba analizirana profila na Instagramu, tako tisti Boruta Pahorja kot tisti Aleksandra Vučića, usmerjena $\mathrm{k}$ iskanju ravnotežja med njunima političnima funkcijama, ki sta vezani na mednarodno politično polje, in zasebnostjo, s pomočjo katere skušata uprizarjati domačijskost in bližino $\mathrm{z} »$ ljudstvom« ter s tem doseči »normalizacijo« svoje osebnosti.

Tako Pahor kot Vučić sta na svojih profilih na Instagramu do novembra 2020 objavila okoli 1600 objav, za potrebe analize pa smo pri obeh predsednikih izbrali obdobje od marca do novembra 2020. V tem obdobju je Borut Pahor objavil 262 objav, Aleksandar Vučić pa 497. Pri tem je Vučić v večini

$\mathbf{4 1 8}$ primerov objavil po več fotografij hkrati, kar pomeni, da je bilo fotografij še vsaj trikrat toliko kot objav. Glede na to, da je zajeto obdobje trajalo 245 dni, lahko ugotovimo, da Borut Pahor večinoma objavi po eno objavo na dan, Vučić pa v povprečju po dve. Že na prvi pogled lahko ugotovimo, da so objave Boruta Pahorja bolj skrbno izbrane, saj posamična objava praviloma vsebuje zgolj eno fotografijo, medtem ko so Vučićeve objave ob pomembnih obiskih pri tujih politikih in političarkah obsežne, vsebujejo več fotografij, pogosto se isto srečanje pojavi v več zaporednih objavah.

Objave obeh predsednikov so bile razvrščene v tematske kategorije, ki so bile prirejene vsakemu predsedniku posebej. Šlo je namreč za poskus sortiranja večjega števila objav, ki pa več kot grobih razmerij med vrstami objav ne pove nič bolj natančnega. Tako lahko pri Pahorju ugotovimo, da je bilo največ fotografij posnetih $\mathrm{v}$ predsedniški palači oziroma na delovnem mestu, skoraj 40 odstotkov, približno 7 odstotkov je bilo neposredno posvečenih boju s pandemijo koronavirusa, na 7 odstotkih fotografij pa so bili otroci, večinoma na obisku v predsedniški palači oziroma je Pahor obiskal njih. Če fotografije z otroki pogojno umeščamo med službene zadeve, je na Instagramu Boruta Pahorja njegovemu opravljanju funkcije predsednika namenjena malo več kot polovica vseh objav na Instagram profilu v izbranem obdobju. Preostanek objav je osebne oziroma zasebne narave. Slabih 7 odstotkov fotografij je iz predsednikovega arhiva, večinoma zasebnega, na primer fotografije iz njegovega otroštva ali pa fotografije njegovega sina. Približno enak delež objavljenih fotografij so portreti predsednika z bolj ali 
maj šaljivimi pripisi, nekoliko več, slabih 9 odstotkov, pa je fotografij iz predsednikove zasebnosti. Prav tako 9 odstotkov fotografij bi lahko uvrstili v kategorijo »fanart«, torej gre za risbice, portrete ali šale na račun predsednika, ki so jih ustvarili večinoma otroci in mladostniki ter komiki. Na fotografijah se je občasno pojavila tudi hrana, a zgolj na treh fotografijah. Hrana, ki je sicer eden od priljubljenih motivov na Instagramu, se je za veliko bolj pomemben del uprizarjanja politike pokazal pri Aleksandru Vučiću. Podkategorija, ki bistveno zaznamuje objave Boruta Pahorja, je šport. V izbranem obdobju je bil šport namreč tema vsaj 46 fotografij, kar je skoraj 18 odstotkov vseh objav. V času prvega vala pandemije je zabeležil tudi dva obiska frizerja.

Profil Aleksandra Vučića na Instagramu je precej manj raznolik in bistveno bolj osredotočen na Vučićevo opravljanje predsedniške funkcije. Slabih 500 objav na tem profilu v izbranem obdobju bi lahko razdelili predvsem na objave, v katerih so zabeleženi Vučićevi stiki z drugimi, predvsem tujimi politiki, ter objave, na katerih je Vučić prikazan na sestankih, obiskih in drugih službenih obveznostih. Takšnih objav je približno 300, torej več kot polovica. Še približno 100 jih je namenjenih Vučićevim obiskom in srečanjem z ljudmi iz vsakdana ali z zaposlenimi v podjetjih, ki jih je obiskal. Tudi te objave bi lahko šteli med službene, kar pomeni, da jih je od skoraj 500 objav vsaj 400 namenjenih prikazovanju Vučićevega predsedniškega dela, ki je skozi fotografije videti kot serija sestankov in obiskov, redno pa so na profilu najavljeni tudi njegovi nastopi na srbskih televizijah, mednarodnih konferencah in drugod. Dodatnih 30 objav je bilo neposredno povezanih s pandemijo, kar je primerljiv delež kot pri Borutu Pahorju, torej približno 7 odstotkov. Večina Vučićevih fotografij tako prikazuje njega med opravljanjem svojega poklica. Večinoma časa je v temnomodri obleki, ko ni fotografiran med sestanki, pa je fotografiran med prebiranjem dokumentov ali podpisovanjem le-teh.

Edina kategorija, ki izstopa pri Vučićevih objavah, je tudi tista, ki se največkrat pojavlja v srbskih satiričnih oddajah; to so fotografije Vučića in hrane. Teh je bilo sicer "zgolj« 24 , kar je ob pogostosti objav zgolj 5 odstotkov vseh objav, pa vendarle so to edine objave, ki so nekoliko bolj osebne narave. Skoraj vsa hrana sodi med tradicionalno srbsko hrano, v večini primerov je šlo tudi za doma pripravljene srbske jedi, ki jih je malical ob obiskih »navadnih državljanov«. Ob prevladujočih objavah o Vučićevem udeleževanju mednarodnih dogodkov in srečanj so objave hrane tiste podobe, $v$ katerih Vučić lahko uprizarja svojo domačijsko moškost delavskega razreda.

Tako Vučić kot Pahor kot predsednika držav v svojih objavah na Instagramu uprizarjata predvsem buržujsko-racionalistično moškost, značilno za mednarodno politiko. Večinoma sta na fotografijah v temnomodrih ali črnih oblekah, v formalnih okoliščinah, ki jih zahteva njuna funkcija. Populističnih objav, torej objav, v katerih se skušata približati predstavnikom 
»judstva« oziroma razredu, ki mu sama ne pripadata, je pri Pahorju bistveno več, vendar v primerjavi z njegovo predsedniško kampanjo 2012 in deloma tudi 2017, ki sta temeljili skorajda izključno na uprizarjanju drugačne, delavske moškosti, je uprizarjanja delavske moškosti bistveno manj. Nekaj »domačijskosti« želi doseči z objavljanjem fotografij, na katerih se ukvarja s športom, a ker gre večinoma za individualne športe, ki ne zahtevajo fizične bližine drugih, je njegovo ukvarjanje s športom bolj značilno za novo, narcisoidno moškost srednjega razreda, kjer je šport predvsem v funkciji skrbi za telo.

Slika 1: BORUT PAHOR MED POČITKOM OB MORJU

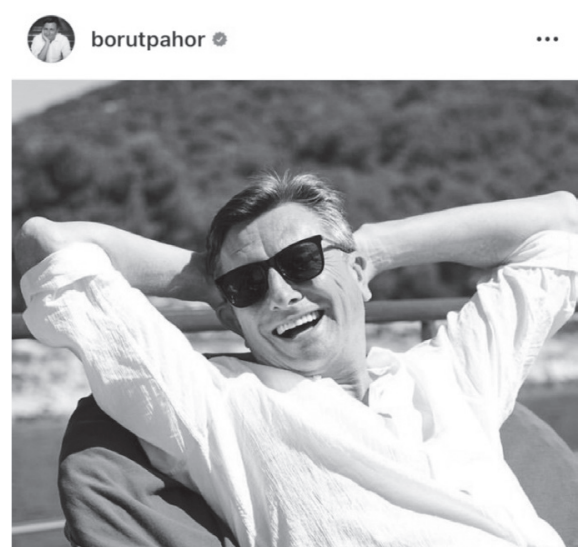

Vir: Instagram Boruta Pahorja.
Slika 2: BORUT PAHOR MED TELOVADBO

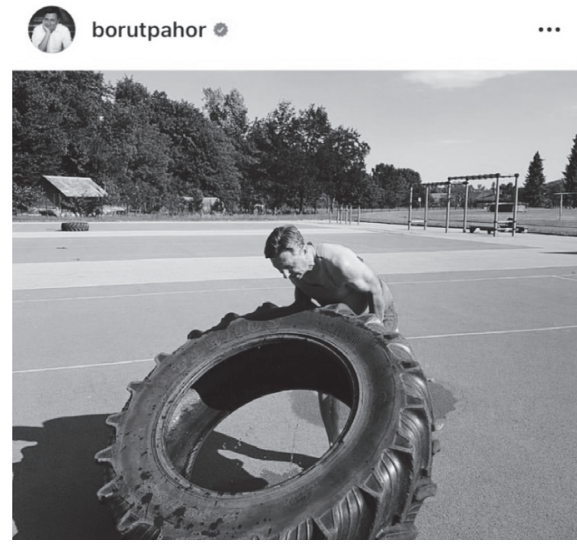

Vir: Instagram Boruta Pahorja.

Pahorjevo uprizarjanje moškosti na Instagramu tako sledi predvsem modelu nove, narcisoidne moškosti, vključno z občasnimi selfiji in fotografijami celotnega telesa v športni opremi. $V$ ospredju so njegova sproščenost $\mathrm{v}$ prostem času, vitko telo $\mathrm{v}$ formi ter skrb zase.

\section{Slika 3: VLADIMIR PUTIN IN BORUT PAHOR}

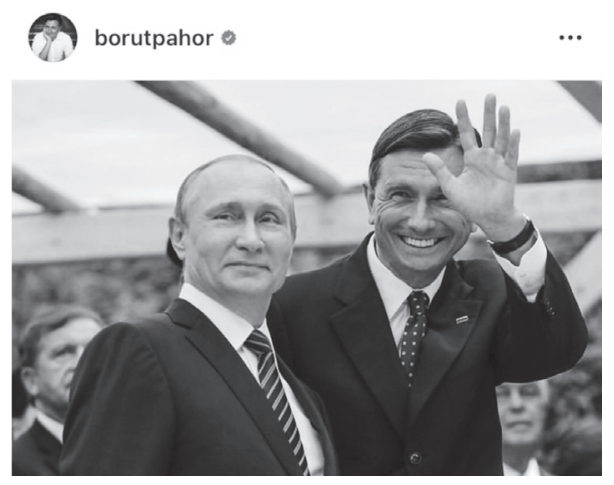

Vir: Instagram Boruta Pahorja. 
Ko uprizarja buržujsko-racionalistično moškost, je pri tem še vedno bližje narcisoidni obliki nove moškosti, ki jo uprizarja s sproščenostjo, nasmehi in v primeru fotografije pred "spomenikom bazoviškim junakom», pred katerim stoji z italijanskim predsednikom Sergiom Mattarello (slika 4), s čustvenostjo in telesno bližino.

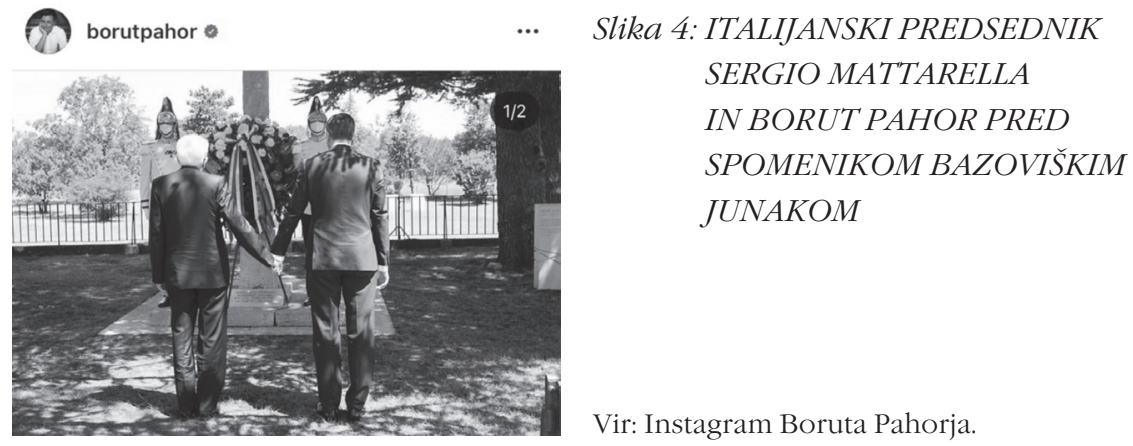

Pri Vučiću uprizarjanje buržujsko-racionalistične moškosti prevladuje in je skorajda v nasprotju z njegovo osebno politično zgodovino, ki temelji na uprizarjanju poudarjene moškosti, ki je bližje Putinu. Instagram je očitno bolj kot domačemu občinstvu namenjen tujini, saj se na njem Vučić skuša samoprikazati kot mednarodno relevanten voditelj, pri čemer pa bolj kot populistične poteze učinkujeta disciplinirano telo in zadržano vedenje. Poleg vseprisotnosti srbske zastave na njegovih objavah je izbor hrane še najbolj nacionalno obarvana dimenzija njegovih objav.

Slika 5: OLIVÉR VÁRHELYI IN

ALEKSANDAR VUČIĆ

NA SESTANKU V BRUSLJU

OB SRBSKI PROJI IN POGAČI
SLIKA 6: ALEKSANDAR VUC̆IĆ

OB VPISU ŠTUDIJA ZA

KOŠARKARSKEGA TRENERJA

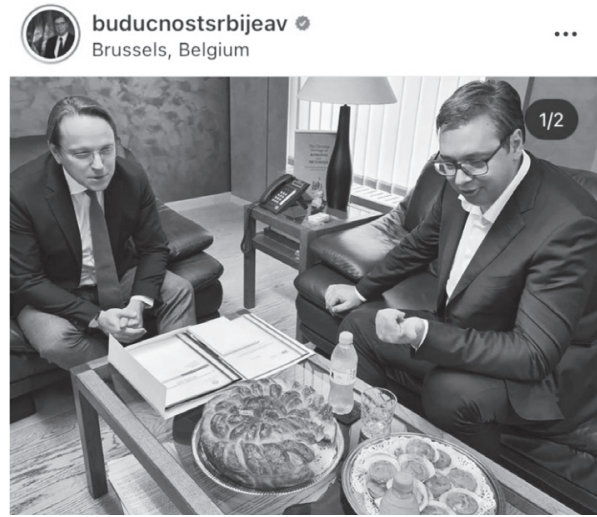

Vir: Instagram Budučnost Srbije. buducnostsrbijeav

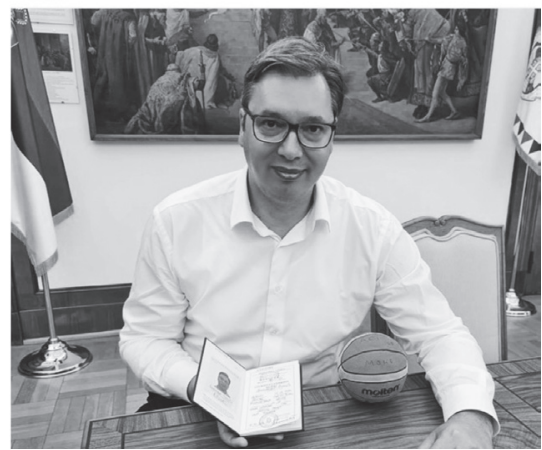

Vir: Instagram Budučnost Srbije. 
Njegove objave sicer niso povsem depolitizirane oziroma so bistveno manj depolitizirane kot Pahorjeve, saj s fotografiranjem s svetovnimi voditelji ilustrira, s katerimi državami je Srbija v najboljšem odnosu, kljub vsemu pa lahko ugotovimo, da so objave na Instagramu bolj kot političnemu delovanju namenjene grajenju podobe Aleksandra Vučića kot politika v mednarodnem političnem polju. Prav tako v objavah ne najdemo uprizarjanja Žrtve ali Übermenscha, kot jih v analizi poročanja o Vučiću navaja Jovanović (2018), ali populizma ter napadanja novinarjev in novinark, kot ga $\mathrm{v}$ analizi nastopov navaja Kulić (2020). Vučić na Instagramu uprizarja predvsem buržujsko-racionalistično, privilegirano moškost, značilno za mednarodno politiko, z občasnimi domačijskimi »premori«, ko si privošči srbsko nacionalno jed.

\section{Slika 7: ALEKSANDAR VUČIĆ NA \\ TERASI PREDSEDNIŠKE \\ PALAČE OB LUBENICI}

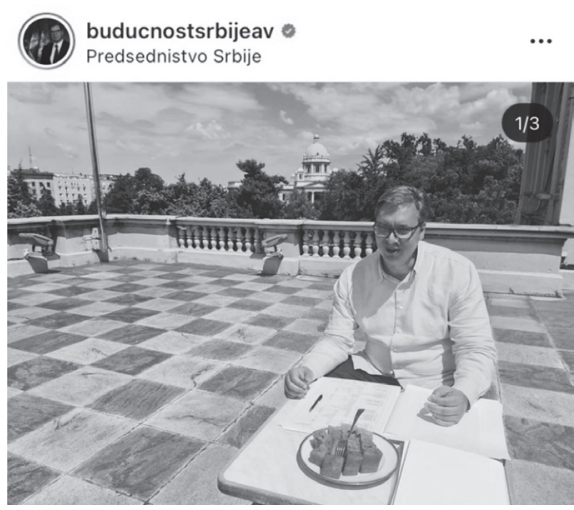

Vir: Instagram Budučnost Srbije.

\section{SLIKA 8: PREMIERKA ANA BRNABIĆ IN ALEKSANDAR VUČIĆ NA POSESTVU VUČIĆEVEGA OČETA}
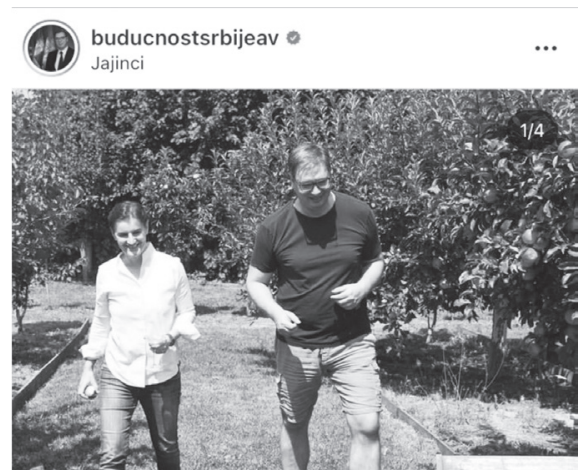

Vir: Instagram Budučnost Srbije.

Izbrane fotografije z Instagrama Aleksandra Vučića odstopajo v tem, da je na njih srbski predsednik prikazan kot gostitelj (na sestanku s komisarjem za širitev EU v Bruslju, na sestanku s premierko na posestvu svojega očeta) ali pa je prikazan ob bolj zasebnih opravilih, kot je vpis na fakulteto, ki ni povezana z njegovo politično funkcijo. Kljub temu Vučić na njih ni prikazan v svoji zasebnosti, kot je to pogosto na fotografijah Boruta Pahorja, temveč je kot politik postavljen v bolj »sproščeno« okolje, pogosto v enakih oblačilih kot med opravljanjem predsedniške funkcije, le na primer brez kravate ali suknjiča.

Pahorjev Instagram je pritegnil precej pozornosti tudi v mednarodnih medijih, v tujih medijih (Associated Press, 2017) so ga opisali kot »mehkega 
populista«, kar se nanaša predvsem na njegovo objavljanje všečnih podob. Tako Pahorjevo kot Vučićevo uprizarjanje politične moškosti na Instagramu bi lahko označili za populistično, vendar pa zaradi same čustvene infrastrukture Instagrama to nima enakega učinka kot na primer populizem Donalda Trumpa na Twitterju. Njun populizem ima za cilj približevanje ljudem, torej izvzemanje iz elite in približevanju ljudstvu, nima pa razsežnosti, ki jo populizmu pripisuje Müller (2016: 35), torej obračanje proti določenim (marginalnim) skupinam v družbi. Pahorjev »mehki populizem« bi lahko na podlagi Instagrama brali kot populizem brez izključevanja, saj Pahor v svojih potezah - po Laschu (2012) narcisoidno - išče potrditev pri vseh, ne glede na njihovo politično ali drugo pripadnost, medtem ko je cilj Vučićevega Instagrama predvsem prikazovanje srbskega predsednika kot enakopravnega v družbi svetovnih voditeljev, a tudi človeka ljudstva.

\section{Sklep}

Instagram kot družbeni medij, ki temelji na podobah in je manj vezan na hipno odzivanje, kot je na primer Twitter, je primeren predvsem za grajenje podobe politične osebnosti na dolgi rok. Brez omejitev tradicionalnih medijev, predvsem uredniških zahtev po relevantnosti, Instagram lahko služi kot mesto, kjer se s podobami gradi personalizirana podoba politike, brez dejanskega bremena politike. Profili politikov in političark na Instagramu so bistveno bolj depolitizirani kot njihove medijske reprezentacije, na njih pa je tudi prostor za uprizarjanje zasebnosti, iz katere nato črpajo svojo politično kompetenco.

Kot smo videli na primeru Boruta Pahorja in Aleksandra Vučića, Instagram omogoča določeno mero nadzora nad vrsto uprizarjanja spola in razreda, saj dopušča širši nabor podob in s tem tudi uprizarjanj. Na profilu Boruta Pahorja na Instagramu je tako približno enak delež »službenih" in zasebnih objav, v katerih uprizarja kombinacijo narcisoidne nove moškosti in v primeru »službenih" objav buržujsko-racionalistične moškosti. Nova, narcisoidna moškost Boruta Pahorja je spogledljiva (Yates, 2010), temelji na bližnjih posnetkih njegovega obraza in fotografijah njegovega telesa $\mathrm{v}$ športni opremi ter iskanju odobravanja občinstva ne glede na njihovo politično prepričanje. Skorajda do konca depolitizirano uprizarjanje politike se ujema s čustveno infrastrukturo Instagrama, kjer Pahor oziroma njegove sodelavke postanejo ustvarjalci všečnih medijskih vsebin na družbenih omrežjih, ki imajo le občasno informativno vrednost in služijo bolj kot zabava ali distrakcija od dnevne politike oziroma njegovih predsedniških obveznosti.

Vučićev profil na Instagramu po drugi strani služi predvsem uprizarjanju buržujsko-racionalistične moškosti in s tem umeščanjem Vučića v mednarodno politično polje. Vpogledov v njegovo zasebnost je manj, ko pa 
do njih pride, gre predvsem za informalizacijo manir (Wouters, 2007), pri čemer se z bolj sproščenim odnosom (brez kravate ali suknjiča, ob tradicionalni srbski hrani ali pa ob zasebnih opravkih na delovnem mestu) še vedno ukvarja s politiko. Vučićev populizem se na njegovem Instagramu kaže predvsem $\mathrm{v}$ poudarjanju nacionalne note, torej s poudarjanjem srbske tradicije $\mathrm{v}$ mednarodnem političnem kontekstu, $\mathrm{s}$ čimer poudarja, da je kljub svoji mednarodni dejavnosti še vedno človek ljudstva. Kot ustvarjalec medijskih vsebin na družbenih omrežjih Vučić oziroma njegovi sodelavci in sodelavke gradijo predvsem na navidezni neskončnosti podob, saj vsak dan objavijo več podob predsednika in s tem ustvarjajo vtis njegove delavnosti in vseprisotnosti.

Čeprav se profila obeh predsednikov na Instagramu razlikujeta v načinu grajenja predsedniške podobe, je obema skupno to, da se v objavah distancirata od svojih političnih prepričanj (Pahor svojih političnih prepričanj sicer od izvolitve za predsednika praktično ne izreka več); medtem ko Pahor to počne s pomočjo objav iz svoje zasebnosti, Vučić to počne z objavljanjem fotografij s srečanj z mednarodnimi voditelji in voditeljicami, s čimer ustvarja podobo umirjenega kozmopolitskega politika $\mathrm{v}$ mednarodnem političnem prostoru, ki pa odstopa od njegove podobe $\mathrm{v}$ domačih, srbskih 424 medijih. V obeh primerih gre za depolitizirane objave, saj v njih ni politične sporočilnosti, temveč imajo cilj grajenje določene podobe predsednika, le da se Pahor v njih bolj nagiba k narcisoidnemu uprizarjanju nove moškosti, Vučić pa h kozmopolitstvu.

\section{LITERATURA}

Altheide, David in Robert Snow (1979): Media Logic. Beverly Hills, London: Sage Publications.

Altheide, David (2013): Media Logic, Social Control, and Fear. Communication Theory 23: 223-238.

Beynon, John (2002): Masculinities and Culture. Buckingham: Open University Press.

Boorstin, Daniel J. (1961/1992): The Image. A Guide to Pseudo-Events in America. New York: Vintage Books, Random House.

Bossetta, Michael (2018): The Digital Architectures of Social Media: Comparing Political Campaigning on Facebook, Twitter, Instagram, and Snapchat in the 2016 U. S. Election. Journalism \& Mass Communication Quarterly 95 (2): $471-$ 496.

Bourdieu, Pierre. 1984. Distinction: a social critique of the judgement of taste. New York, London: Routledge.

- 1996/2001. Na televiziji. Ljubljana: Krtina.

Butler, Judith (2006/1990): Gender Trouble. New York: Routledge.

Corner, John (2000): Mediated persona and political culture: Dimensions of structure and process. European Journal of Cultural Studies 3 (3): 386-402. 
Corner, John in Dick Pels (2003): Media and the Restyling of Politics. London: Sage Publications.

Couldry, Nick, Andreas Hepp (2013: Conceptualizing Mediatization: Contexts, Traditions, Arguments. Communication Theory 23: 191-202.

Crnović, Deja (2014): Uprizarjanje moškosti v predvolilni predsedniški kampanji 2012: Primer Boruta Pahorja. Družboslovne razprave, XXX (2014), 75: 49-64.

--. (2017): Performativnost spola v medijskih reprezentacijah družbe. Doktorska disertacija. Ljubljana: Fakulteta za družbene vede.

Dayan, Daniel in Elihu Katz (1992): Media events. The Live Broadcasting of History. Cambridge: Harvard University Press.

Driessens, Olivier (2010): Personalization according to politicians: A practice theoretical analysis of mediatization. Communications 35 (3): 309-326.

Ekman, Mattias in Andreas Widholm (2015): Politicians as Media Producers: Current trajectories in the relation between journalists and politicians in the age of social media. Journalism Practice 9 (2): 78-91.

Gilroy-Ware, Marcus (2017): Filling the Void: Emotion, Capitalism and Social Media. London: Repeater Books.

Hepp, Andreas (2013): Cultures of Mediatization. Cambridge: Polity Press.

- in Nick Couldry (2010): Introduction: media events in globalized media cultures. V: Media events in a global age, ur. Nick Couldry, Andreas Hepp in Friedrich Krotz, 1-20. Abingdon: Routledge.

Hjarvard, Stig. (2008): The Mediatization of Society. A Theory of Media as Agents of Social and Cultural Change. Nordicom Review 29 (2): 105-134.

Hooper, Charlotte (2001): Manly states: masculinities, international relations, and gender politics. New York: Columbia University Press.

Iyengar, Shanto (1991): Is Anyone Responsible? How Television Frames Political Issues. Chicago: University of Chicago Press.

Jovanović, Srđan Mladenov (2018)»You're Simply the Best«: Communicating Power and Victimhood in Support of President Aleksandar Vučić in the Serbian Dailies Alo! and Informer. Journal of Media Research 31 (2): 22-42.

Kalb, Don (2011): Introduction. V: Headlines of Nation, Subtexts of Class: WorkingClass Populism and the return of the Repressed in Neoliberal Europe, ur. Kalb in Halmai, 1-36. New York, Oxford: Berghahn Books.

Kalb, Don in Gabor Halmai (2011): Headlines of Nation, Subtexts of Class: WorkingClass Populism and the return of the Repressed in Neoliberal Europe, ur. New York, Oxford: Berghahn Books.

Kulić, Milica (2020): Populist Communication in the Post-Truth Age: A Comparative Analysis of Treatment of Journalists by Donald Trump and Aleksandar Vučić. Journal of Regional Security 15 (1): 75-108.

Laclau, Ernesto (2008): O populističnem umu. Ljubljana: Sophia.

Lalancette, Mireille in Vincent Raynauld (2019): The Power of Political Image: Justin Trudeau, Instagram and Celebrity Politics. American Behavioural Scientist 63 (7): 889-924.

Lamont, Michele (2000): The Dignity of Working Men: Morality and the Boundaries of Race, Class, and Imagination. New York: Russell Sage Foundation. 
Larsson, Anders Olof (2017): Top Users and Long Tails: Twitter and Instagram Use During the 2015 Norwegian Elections. Social Media + Society, April-June, 1-12. Liebhart, Karin in Petra Bernhardt (2017): Political Storytelling on Instagram: Key Aspects of Alexander Van der Bellen's Successful 2016 Presidential Election Campaign. Media and Communication 5 (4): 15-24.

Luthar, Breda (1998): Poetika in politika tabloidne kulture. Ljubljana: Znanstveno in publicistično središče.

-- (2008): Proizvodnja slave. Politika v popularni kulturi. Ljubljana: Založba FDV.

--, ur. (2014): Kultura in razred. Ljubljana: Fakulteta za družbene vede.

Marland, Alex (2012): Political Photography, Journalism, and Framing in the Digital Age: The Management of Visual Media by the Prime Minister of Canada. The International Journal of Press/Politics 17 (2): 214-233.

Mazzoleni, Gianpetro in Winfried Schultz (1999): Mediatization of Politics: A Challenge for Democracy? Political Communication 16: 247-261.

Mouffe, Chantal (2018): For a Left Populism. New York, London: Verso.

Ochs, Elinor (1992): Indexing Gender. Dostopno prek http://www.sscnet.ucla.edu/ anthro/faculty/ochs/articles/92index_gen.pdf, 29. 10. 2013.

Ponce de Leon, Charles. L. (2002): Self-exposure. Human-interest Journalism and the Emergence of Celebrity in America 1890-1940 Chapel Hill in London: The University of North Carolina Press.

426 Riabov, Oleg, in Tatiana Riabova (2014):

Skrbiš, Zlatko in Ian Woodward (2013): Cosmopolitanism. Uses of the Idea. London: Sage.

Street, John (2003): The Celebrity Politician: Political Style and Popular Culture. V: Media and the Restyling of Politics, ur. John Corner in Dick Pels, 85-99. London: Sage Publications.

- (2004): Celebrity Politicians: Popular Culture and Political Representation. British Journal of Politics \& International Relations 6: 435-453.

Van Santen, Rosa in Liesbet van Zoonen (2009): Popularization and Personalization in Political Communication: A Conceptual Analysis. Conference Papers International Communication Association (1-38). International Communication Association.

-- in Liesbet van Zoonen (2010): The Personal in Political Television Biographies. Biography: An Interdisciplinary Quarterly 33 (1): 46-67.

-- (2012): Popularization and Personalization. A Historical and Cultural Analysis of 50 Years of Dutch Political Television Journalism. Amsterdam: University of Amsterdam.

Van Zoonen, Liesbet (1994): Feminist Media Studies. London: SAGE Publications.

- (2005): Entertaining the Citizen: When Politics and Popular Culture Converge. Oxford: Rowman \& Littlefield Publishers, INC.

- (2006): The personal, the political and the popular. A woman's guide to celebrity politics. European Journal of Cultural Studies 9 (3): 287-301.

Wahl-Jorgensen, Karin (2019): Emotions, Media and Politics. Cambridge: Polity Press. 
Wodak, Ruth (2011): Disenchantment with Politics and the Salience of Images. V: Images in Use, ur. Matteo Stocchetti in Karin Kukkonen, 69-88. Amsterdam: John Benjamins.

Wouters, Cas (2007): Informalization: Manners and Emotions Since 1890. Los Angeles, Calif: SAGE Publications Ltd.

Yates, Candida (2010): Spinning, spooning and the seductions of flirtatious masculinity in contemporary politics. Subjectivity 3 (3): 282-302.

VIRI

Aleksandar Vučić (@buducnostsrbijeav). Dostopno prek https://www.instagram. com/buducnostsrbijeav, 10. 3. 2021.

Associated Press (2017): Barbie, and not a bad guy: meet Borut Pahor, Slovenia's Instagram president. Dostopno prek https://www.theguardian.com/world/ 2017/mar/08/borut-pahor-slovenia-instagram-president, 10. 3. 2021.

Borut Pahor (@borutpahor). Dostopno prek https://www.instagram.com/borutpahor/, 10.3. 2021.

Hinsliff, Gaby (2019): How Instagram became the politicians' playground. Guardian 10. 3. 2019. Dostopno prek https://www.theguardian.com/technology/2019/ mar/10/how-instagram-became-the-politicians-playground, 20. 10. 2020.

N1 Srbija (2017): Vučić snimio predizborni spot »Vučiću, pederu!«. Dostopno prek http://hr.n1info.com/Regija/a182408/Vucic-snimio-predizborni-spot-Vucicupederu.html, 10. 3. 2021. 